\title{
Application Domains for a Location-based Mobile Application Creator
}

\author{
http://dx.doi.org/10.3991/ijim.v9i3.4470 \\ J. Pirker ${ }^{1}$, C. Gütl ${ }^{1,2}$, P. Weiner ${ }^{1}$ and V. M. Garcia-Barrios ${ }^{3}$ \\ ${ }^{1}$ Graz University of Technology, Graz, Austria \\ ${ }^{2}$ Curtin University, Perth, Western Australia \\ ${ }^{3}$ Galileo University, Guatemala City, Guatemala
}

\begin{abstract}
In recent years, the use of mobile applications and computer-based games as pedagogical tools has become more and more popular. Additionally, many mobile devices enhance user experience by providing different sensors, e.g. to deliver location-based educative information. In this article we introduce an online tool for easily creating location-based mobile applications that combine teaching and gaming activities to make users aware of their current environment or situation. First, we briefly present the Locationbased Mobile Application Creator (LMAC), an online framework for creating such mobile solutions and discuss potential application scenarios. Then, we introduce our first mobile application for educational purposes created with LMAC in more detail: a game-based scavenger hunt for children enabling them to learn facts about the city of Graz, Austria. Similar to a traditional scavenger hunt, users are able to gather geo-referenced information using mobile devices (smartphones and tablets) to learn about the environment in a playful way. With LMAC, teachers can easily create individual scavenger hunts adapted to the current subject matter. This paper is an extended version of our work published at the IMCL-conference in 2014.
\end{abstract}

Index Terms-location-based mobile app, gamified scavenger hunt, mobile learning

\section{INTRODUCTION}

The use of mobile media devices, such as smartphones and tablets, is becoming increasingly popular, frequent, and integrated into the daily life of children. A study from Common Sense Media [2] on children's media use, conducted in America in 2011 and 2013, shows the dramatic increase of the number and use of mobile devices. While in 2011 only $52 \%$ of American households had a mobile media device at home, in 2013 the number had increased to $75 \%$. In $2011,8 \%$ of the 0 to 8 year olds were using such devices every day; within two years the number went up to $17 \%$. In 2013 , the most popular activity on these devices among 0 to 8 -year-olds was playing games $(63 \%)$. When asked which type of mobile apps they used, the most popular ones were educational games $(43 \%)$, games that were just fun $(42 \%)$, and creative apps $(38 \%)$.

These statistics point out the value of integrating mobile devices more into learning settings. Many teachers already use mobile devices in classrooms, and educational games as well as gamified applications are becoming more popular in pedagogical settings. Carefully designed educational applications with game-like mechanics and interactivities can be excellent teaching and training tools [3][4]. Games can help in practising problem solving, excel in demon- stration, can give new insights, and can teach facts in a more visual way [5]. Thus, more and more applications combine learning content with game design elements to make learning more engaging. Furthermore, an increasing number of teachers do not only want to use existing games, they also want to adapt the content according to their course content or even want to independently create games with personalised content.

A feature that is unique to educational mobile applications and games is the support of location-based learning. Games such as Google's Ingress ${ }^{1}$, which use geographical information and require the user to actively find places, are very popular among smartphone users [6]. Several educational applications use geographical information delivered by mobile devices to make pupils aware of their environment. Many authors have shown successful examples of such location-based learning applications [7][8][9]. Most of the existing solutions focus on educational experiences such as collaborative or explorative learning, and do not, or only partially, include game design elements. Additionally, many disregard requirements such as platform independence, software flexibility or reusability.

In this paper we introduce a framework that enables a simplified creation of platform-independent locationaware applications, which can be designed either with a focus on simple information delivery (e.g. to create interactive and mobile tourist guides) or as playful scavenger hunts (e.g. to create scavenger hunt games for children to teach facts about a special region). This allows, for instance, teachers to easily create a playful learning experience for their pupils. As one potential application, we describe an app, which was created to teach children aged 8-10 facts about the historic city centre of Austria's city Graz, in more detail.

This paper is an extended version of work introduced at the International Conference on Interactive Mobile Communication Technologies and Learning 2014 in Thessaloniki [1]. In this extended version we discuss different potential application domains and selected scenarios, the architecture of the LMAC, first experiments with the first created scavenger hunt for children, and preliminary findings in more detail.

\section{BACKGROUND}

There has been extensive work on playful learning applications for children. In the following section we discuss different aspects of learning applications, which are either

\footnotetext{
${ }^{1}$ https://www.ingress.com
} 
PAPER

designed as games (learning games), or use game design elements to augment learning scenarios (gamified applications [10]). After that, we will highlight existing work on mobile learning games with a focus on applications that use geographic information.

\section{A. Using Game Design Elements in Education}

The use of game design elements in non-game contexts to motivate users is becoming more and more popular in interaction design and digital marketing. The areas of use are widespread and include sports, health, education and manufacturing. Gamification uses different techniques to engage users so that they complete a certain task [11]. Such techniques include reward systems, such as achievements and badges, or feedback systems such as points and progress bars [12]. Another technique makes use of the competitive spirit of the user. Here, the rewards for accomplished tasks are also presented to other users and leader board and ranking information is provided [13].

Different applications use the concept of engagement with game-like interaction design to enhance learning content. The following examples use gamification strategies to enrich learning with fun elements: Duolingo ${ }^{2}$ is a free web platform for learning languages while translating websites. It uses skill points and bonuses to engage its users [14][15]. Khan Academy ${ }^{3}$ provides free learning materials, such as videos and assignments, on different subjects. It includes a skill tree where the user can achieve different skill levels. Additionally, the user receives points linked to his progress and can earn badges [16][17]. Ribbon Hero $2^{4}$ is a Microsoft Office add-in game to teach users how to interact with the ribbon interface. In this game, the user follows Microsoft Office's mascot Clippy on a journey through time to help him solve several tasks in the Office Suite [18][19].

Even though the term gamification is relatively new, many games and applications designed in earlier years would fit the definition. This also includes non-digital activities, such as a traditional scavenger hunt, which is still often used for educational purposes [20].

Using mobile devices as the medium for these educational applications poses different advantages. Every year the number of households with smartphones and tablets is increasing [2]. These devices are in general more affordable than PCs or laptops. Due to their portability they can provide functionalities and activities without being supported by other devices. Hence, location-based dynamic learning content can be integrated as well. In the next section, different mobile applications are introduced that use geographic data to enhance the learning experience, by taking into account the learners' environment.

\section{B. Mobile Geo-based Applications for Learning}

The $2^{\text {nd }}$ of May 2000 was the day of a big leap for the geo data available for the average person. The U.S. government discontinued the use of 'Selective Availability', which was an intentional degradation of public GPS signals. This deactivation made GPS more accurate and responsive for civil users [21]. This date was also significant for GPS enthusiasts who developed new ideas for using the technology, which was no longer technically restrict-

\footnotetext{
${ }^{2}$ https://www.duolingo.com/

${ }^{3}$ https://www.khanacademy.org/

${ }^{4}$ http://www.ribbonhero.com/
}

ed. Just one day after the deactivation, Dave Ulmer, a computer consultant, hid a navigational target in the woods to test the accuracy of the GPS. He posted the coordinates of the target $\left(\mathrm{N} 45^{\circ} 17.460 \mathrm{~W} 122^{\circ} 24.800\right)$ and his idea, which he called "Great American GPS Stash Hunt", in a GPS users' group on the Internet. The other participants had to search for the stash using only a GPS receiver. Geocaching, one of the first games including geo data, was born [22]. Different types of geocaching support different goals. While traditional geocaching contains only the search for a logbook and special items, Earthcache ${ }^{5}$, for instance, aims to discover and learn natural things at different geologically interesting points [23].

The launch of smartphones, which brought location data to a broader audience, made geo-data even more significant. A vast number of location-based services and applications in different areas, such as navigation, user tracking, or personalized advertisement, were developed [24]. Thus, geographic information can also be used to provide location-based information. The 'Field Trip' app from NianticLabs@Google, for instance, informs the user about local attractions and businesses. Users can select a place and get a flashcard with a description, the location on Google Maps, and some pictures [25].

Different capabilities of these devices allow even further functionalities for games and apps. The combination of geographical data and augmented reality in particular offers many opportunities for applications with educational purposes. With "Reliving the Revolution", Karen Schrier created one of the first mobile, location-based games for learning about history [26]. The game simulates the Battle of Lexington, which initiated the American Revolution, at the site of the battle in Lexington, Massachusetts. She describes the game as follows: "To play the game, participants try to figure out who fired the first shot at the Battle of Lexington-a mystery that still remains today. To do this, participants explore the historic site of Lexington Common, which still features some of the same buildings and structures from 1775. They use the handheld computers to find and access hot spots of information in specific locations around Lexington" [27].

Several authors have presented mobile applications that support educational location-based tours with different forms of input and for different devices. Jones and Willis [7] describe an explorer application for touch devices with an underlying Windows Mobile operating system. To create these applications, a Content Management System is used, which allows teachers to add content, such as user activities, quizzes, or information linked to specific geo points.

Heimonen et al. [8] introduce the location-based collaborative mobile learning platform Seek'N'Share. The platform consists of an editor interface and a mobile Android application designed for smartphones or tablets. In the editor interface, a teacher can create learning content for specific areas or points of interests. Using the application created, pupils can collect information about the areas or points of interest and create a multimedia presentation with this information. The authors evaluated a finished application, which was designed as an assignment for learning about the history of the local Tammerkoski rapids area, with six school children aged between 13 and 14 . The feedback was positive overall with the application

\footnotetext{
${ }^{5}$ http://www.earthcache.org/
} 
PAPER

being rated as useful and more inspiring to learn with than when learning in class, or when using traditional learning methods. Another example of a web-based authoring tool for creating location-based applications is Tidy City. The finished applications are scavenger hunt-like games designed to engage the user in a search for riddles, which are all shown on a map. Tidy City is designed with a focus on entertainment; however, it can also support educational scenarios [28].

In the next section we will introduce LMAC, a tool that uses similar methods, but is designed with a focus on interoperability, user engagement, and interactive design.

\section{The LocAtion-BAsed Mobile ApPlicAtion CREATOR}

To allow the individual and easy creation of scavenger hunts we developed the Location-Based Mobile Application Creator (LMAC) tool. In general, LMAC is used to create mobile location-aware applications for different application possibilities, e.g. playful scavenger hunts or guided tours. LMAC was designed with the objective of creating a framework, can be used easily by nonprogrammers, and can be used to create engaging, mobileaware applications which are platform and device independent and applicable for a wide range of user groups. As can be seen in Figure 1, LMAC consists of two major parts: (1) the editor interface, which is used to create individual location-aware applications; (2) the created mobile applications, which use the data setup in the editor.

The editor interface is described in the next section, and after that the main concepts of the automatically created mobile applications are outlined. Following that, we describe different potential applications.

\section{A. Creating Individual Applications with the Location- Based Mobile Application Creator}

LMAC is designed as an online editor for creating mobile applications, which use geographical information and can trigger events when a special location is close. LMAC provides a web-interface to easily create new routes, add locations to a route, and link information, media, or activities to these locations. In Figure 2, for instance, a route called "Universities of Graz" is created. Each tour has a unique ID so that the creator can easily edit the tour at a later date, and so users who know the ID can easily access the mobile application. The user can add different locations (target points) for a specific tour by either selecting a location from an existing list, adding a new location by entering geographical data, or clicking on the location on the map. A route can either be set up as a "fixed route", which allows a pre-set order of target points to be set up, or as an "undefined route". In the second case the nearest target point is always shown on the mobile application interface. These setup modi allow the creation of guided or non-guided location-based information tours, or playful scavenger hunts.

Each target point is linked to an activity which is triggered when the user of the mobile app is close to this point. Activities supported by the current prototype, which can be linked to locations, include either (1) Location Information such as text, hyperlinks or media data (images, sound or video), or (2) Location Interactivities such as single/multiple-choice questions or open-ended questions.
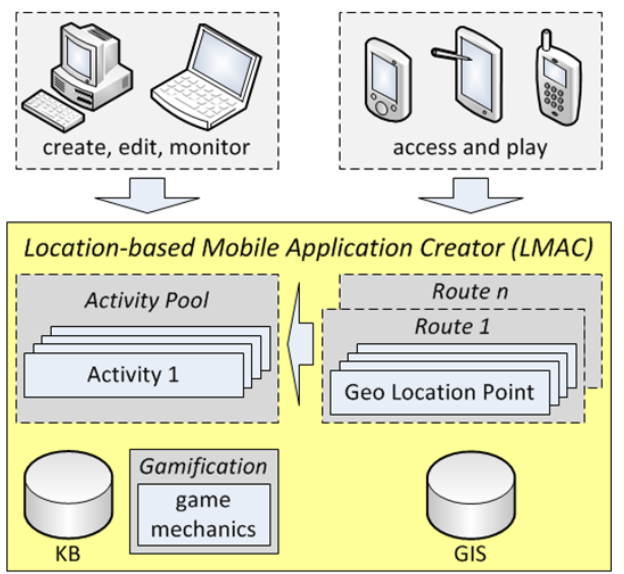

Figure 1. LMAC consists of two major components: the editor interface to create location-aware activities and the created application.

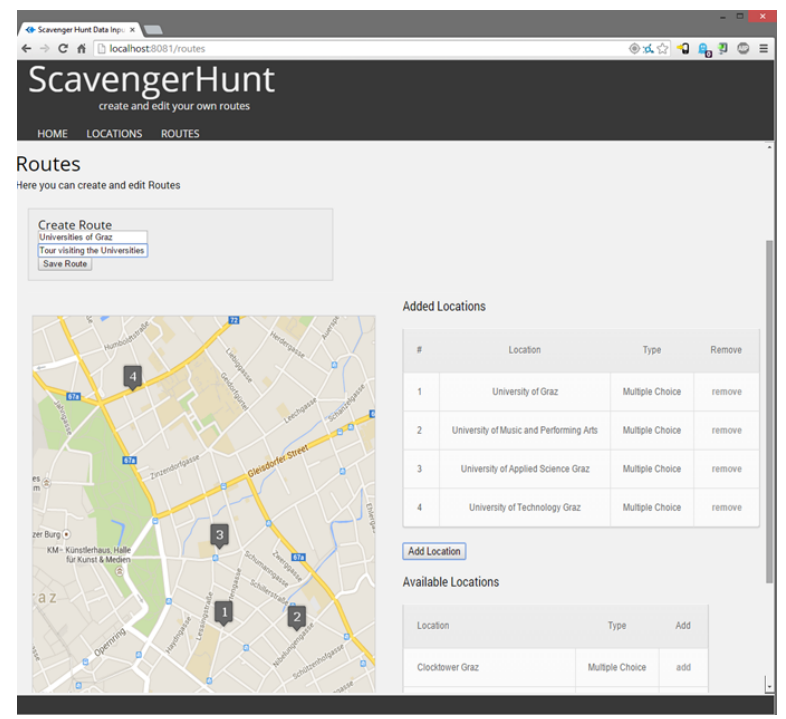

Figure 2. The web-administration interface of LMAC, which indicates the current route and enables adding new locations with different activities such as multiple-choices quizzes.

\section{B. Mobile Applications created with the Location-Based Mobile Application Creator}

The interfaces of the mobile applications, created with the LMAC web platform, are mobile web applications designed with a focus on cross-platform compatibility. Thus, jQuery ${ }^{6}$ Mobile, a HTML5-based system for creating responsive web sites and apps, is used. This allows the application to be used on different mobile devices with different operating systems, and does not limit use to Android or iOS.

The mobile applications can either be accessed by entering a URL with the specified unique ID or by selecting a route from the open-access routes in the overview list (see Figure 3, left picture).

The interface of a running scavenger hunt is based on a map view (see Figure 3, right picture), which displays location and distance to the closest target point. As soon as the user gets close to the target point, the linked activity pops up. In the case of linked Location Information, the 
user has to process the information (e.g. read a text or watch a video), and will then receive the location data of the next target point. In the case of a linked Location Interactivity, the user has to complete it (e.g. answer a question as seen in Figure 4) before he gets the next target point.

In the next section, we discuss in more detail an educational application which is used to teach school children aged 8-10 about the city they live in.

\section{The Architecture}

Figure 5 illustrates a basic overview of the LMAC architecture. Node.js ${ }^{7}$ is an asynchronous event-driven framework and is used as a basis for the application to handle the communication between database, the mobile web application and the date input page. With the help of the database wrapper mongoskin ${ }^{8}$, the document-oriented database MongoDB is connected to Node.js. All locations and routes are saved in this database.

On the client-side, an editor interface, the data input page, is used to create, edit, and save locations and routes. This interface is HTML5 based and uses jQuery and a Google Maps plugin to enhance interactivity and usability. Basic features for web applications such as routing are integrated with the help of the Express-Web-Framework ${ }^{9}$ for Node.js. This allows communication with the server and the database via RESTful services and JSON.

The HTML5-based mobile web application was created with jQuery Mobile and uses a Google Maps Plugin to display and interact with the geographic information. It also uses the RESTful services to get route information. Since location information is saved and connected to the route, the mobile web application only communicates with the database to receive the route information. To maintain flexibility and independence, the mobile web application runs on its own basic Apache Webserver.

\section{Application Domains and Selected Scenarios}

The software is flexible and reusable, thus allowing use in different application domains. LMAC was mainly designed to create applications for three main domains:

- Education, such as teaching the history of a city, landmarks, or pointing out geological highlights while hiking

- Tourism and exploration of unknown areas, including guided city tours or exploring foreign places, such as a tour through a large university campus

- $\quad$ Sport and leisure time, which include physical exercises and outdoor games.

Applications can be created either as simple applications with informatory setting, or as playful scavenger hunts with game design elements to make the experience more engaging. The hunt for the next target points linked to interactivities creates a sense of a game. Thus, informative exploration settings as well as interactive scavenger hunts are possible. This concept shifts the levels of applicability of LMAC from a simple and individual information push/pull principle to a flexible and activity-based collaboration technology for knowledge acquisition.

\footnotetext{
${ }^{7}$ http://nodejs.org/

${ }^{8} \mathrm{https}: / /$ github.com/kissjs/node-mongoskin

${ }^{9} \mathrm{http}: / /$ expressjs.com/
}

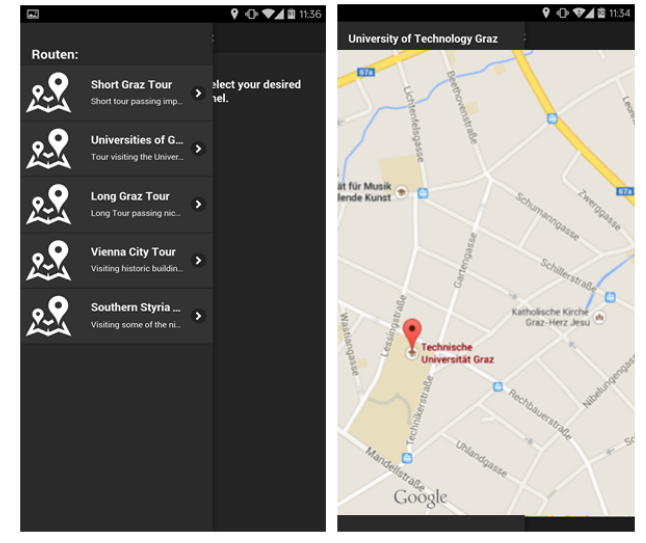

Figure 1. Interface of the mobile client - overview of different accessible routes (left) and map view which indicated the next target.
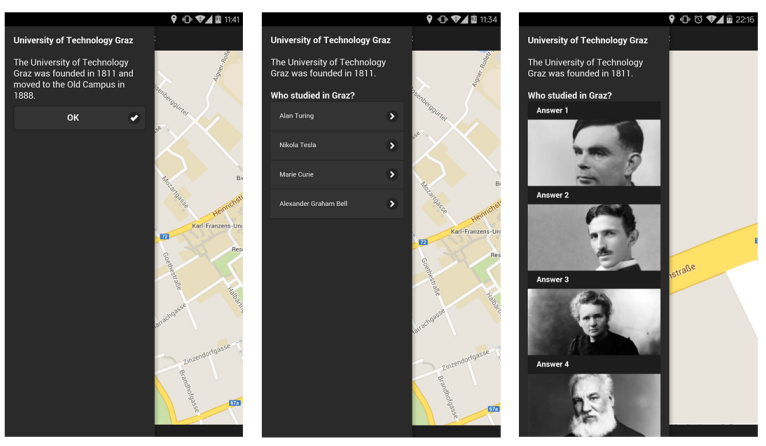

Figure 2. Information or activities such as questions pop up when the user is close to the target location.

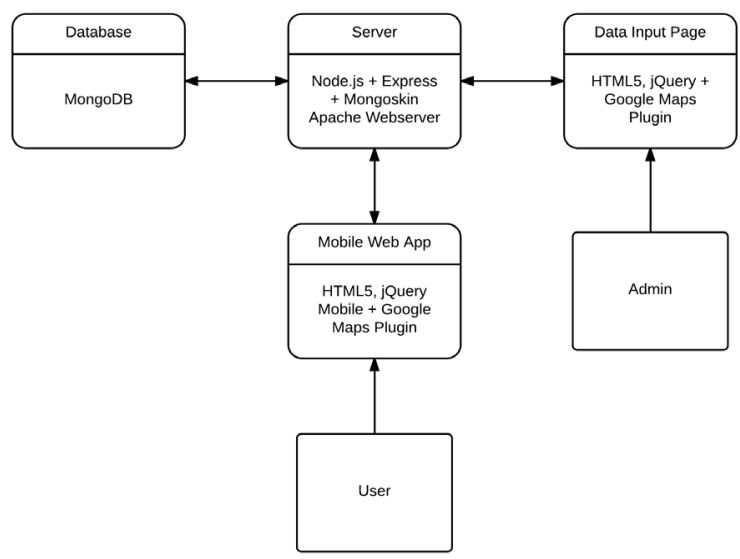

Figure 3. LMAC prototype architecture.

A scavenger hunt can be designed either in a collaborative or competitive way. A collaborative scavenger hunt can be achieved by creating different LMAC applications for different users (or group of users), with these applications following a common goal. Thus, because the knowledge and skills of many persons are required to find the final target point, the users have to work together to reach the common goal. In a competitive setup (i.e. one comparative application for many users), users try to find all the target points on their own (or in groups), and try to be the first (or quickest) to find the final target point. This principle is very relevant as it opens more application scenarios that go beyond education, e.g. to coax groups of tourists to visit certain sightseeing points and interact with the environment, or to motivate families with children to 
PAPER

walk\&play (instead of the "boring walk-around" of adults, from the point of view of children). Also within this context, LMAC allows personalised tours to be defined; this can be achieved by providing different scavenger hunts for the same route. E.g. the same route being more informative (or "dry", for adults), more gamified (or "fun" for children), more active (or "physically challenging" for sportsmen), more intellectually challenging (or "nerdy" for quiz-lovers), or even more specialised (or "hands-on" for geocachers), and so on.

In elementary school, children usually learn about their local environment. This includes historical facts, places, and architectural information about the city they live in. Usually, children learn these facts either in class or during a school excursion. Over the course of these excursions the teacher explains the facts and the pupils have to answer questions about the learned facts after the excursion. With a playfully designed (inter)active and collaborative/competitive scavenger hunt application the pupils are able to split up into small groups to learn about the environment without being dependent on the information or advice of the teacher (please note that we do not mean that they should walk around alone and unsupervised, which could put them at risk). The interactive nature of such group-oriented applications encourages pupils to answer questions about the environment immediately. This active and immediate involvement with the environment supports the constructivist, self-guided and discoverylearning paradigms.

In the next section we discuss our first experiment with an educational application which was designed to teach young students historic facts about the city of Graz.

\section{SCENARIO: EDUCATIONAL SCAVENGER HUNT - HISTORY OF GRAZ}

In an initial field study, we created a mobile application for teaching 8 to 10 -year-old primary school children (grade 3 and 4) historical facts about the historic centre of the Austrian city of Graz and the province. The setup is designed to be an extension of the classroom teaching and can be integrated in the form of a group excursion. The explorative and playful character of the scavenger hunt stimulates the children's curiosity to find the information and answers to the quiz on their own.

The aim of the application is for the pupils to learn background information about different historical buildings (see Figure 6). To achieve a playful and collaborative setting, the school children work together in groups of 2-3 and have to find information about the buildings in order to answer the questions on their own. Similar to a traditional scavenger hunt, the first pupil group to reach the final target point will get a (didactical) reward from the teacher.

In a preliminary experiment, two important points were discovered. First, three and four-grade students are not very (or not at all) experienced in reading maps. With this app, they had to learn very quickly how to read and use them in order to be able to play the game. Thus, with a view to future development, it will be necessary to add optional on-boarding tasks to the application to make it easier for young users to learn how to interact with such maps. Also, additional map-interface elements, such as a compass or direction guides should help them to use the map and the application.

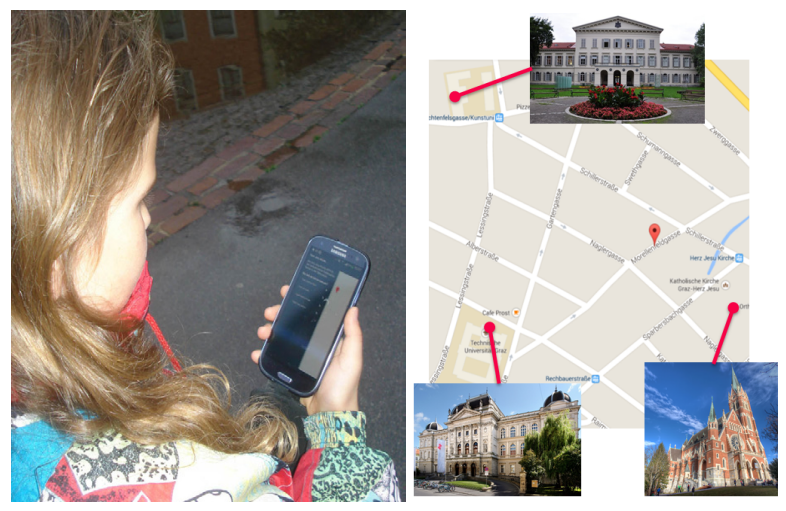

Figure 4. Children use the mobile device to explore areas of interest and find information about different buildings and places.

Furthermore, the experiment revealed that children are often not aware of street and building names, even though they are familiar. For younger students it would make sense to add tasks and activities to the basic scavenger hunt application to make them aware of these names as well.

Quiz tasks and assignments were designed to engage students to find the answer by exploring the environment and gaining different information on the object. An informal post-test two days after the experiment indicates successful learning outcomes. However, the current prototype doesn't support any tips or hints regarding how to find the information or how to answer the question alternatively, which can be very frustrating for children. In a future version, a hint system which can be triggered on demand or after a specific amount of time, should be integrated.

Observations indicate that the children were motivated intrinsically and wanted to play the game and solve the quizzes willingly. However, several security issues were discovered as well. The participants were very focused on the mobile device and often ignored or forgot the threat of road traffic and environment obstacles, which makes supervision absolutely necessary.

\section{DISCUSSION}

There are clearly many limitations, areas of improvement, and ideas for future work. A more detailed evaluation of the current prototype with different user groups is an integral part of measuring effectiveness and of discovering issues and thus allowing for areas of improvement to be identified. For the first evaluation phase at a larger scale we will introduce the prototype of the scavenger hunt in Graz to a larger group of school children aged 810. In a subsequent evaluation phase we will ask school teachers to use the editor interface of LMAC to create a new scavenger hunt and use this scavenger hunt as an assignment for their class. A key element of the evaluation is the usability of the interface with focus on the map display (direction to target, visited places, etc.) and additional audio signals.

Different mobile devices support different technologies and features. We also want to improve access to the sensor signals to be able to improve the interactivity and accuracy of the applications. On the administration interface, more possibilities for settings will be integrated.

Additionally, to create a more game-like character we will introduce more game-design elements, such as points, badges, ratings, and progress bars to enable teachers not 
only to create scavenger hunts but also to further gamify these applications, retrace the learning performance of the mobile users, and of course enhance the look and feel of the game from users' feedback. Again, we plan to undertake a user study with two different stakeholder groups in the same setup. Based on these results, we can compare the different motivators and also discuss different learner types.

\section{CONCLUSION}

In this article we have presented an online tool that allows the creation of individual scavenger hunts. We have described the basic principles of this web-based software framework and introduced potential application domains for application created by this tool. Furthermore, we have introduced an initial application scenario of a playful location-based scavenger hunt created with this software, which is particularly designed for elementary school pupils. The first results in a preliminary study suggest the necessity of further developments in the domains of (1) usability, (2) advanced playful design, (3) further interaction possibilities, (4) improved technology and feature support, and (5) user studies with different target groups. Our main contributions can be summarized as follows: 1) a cross-platform, flexible, and reusable online tool for creating individual location-based mobile applications; 2) a sample mobile application for children to learn facts about the city Graz in a playful way.

\section{REFERENCES}

[1] J. Pirker, C. Guetl, P. Weiner, V.M. Garcia-Barrios, and M. Tomintz, "Location-based Mobile Application Creator - Creating Educational Mobile Scavenger Hunts", in Interactive Mobile Communication Technologies and Learning (IMCL), 2014 International Conference on, vol., no., pp.160,164, 13-14 Nov. 2014 http://dx.doi.org/10.1109/imctl.2014.7011124

[2] Common Sense Media., “Zero to Eight: Children's Media Use in America", 2013, [Online]. Available: https://www.commonsense media.org/research/zero-to-eight-childrens-media-use-in-america2013.

[3] E. Castronova, Synthetic worlds: the business and culture of online games. Chicago, IL: The University of Chicago Press, 2005.

[4] M. Prensky. "Computer games and learning: Digital game-based learning," Handbook of computer game studies, vol. 18, pp. 97$122,2005$.

[5] J. Schell, The Art of Game Design: A Book of Lenses. Boca Raton, FL: Taylor \& Grancis Group, 2008.

[6] Ingress Website. Ingress by NianticLabs@Google [Online]. Available: https://www.ingress.com/.

[7] C. M. Jones and M. Willies, "Edutainment in the field using mobile location based services," in Proceedings of the $21^{\text {st }}$ Annual Conference on the Australian Computer-Human Interaction Special Interest Group: Design: Open 24/7, pp. 385-388, Melbournce Australia, 2009. http://dx.doi.org/10.1145/1738826.1738904

[8] T. Heimonen, M. Turunen, S. Kangas, T. Pallos, P. Pekkala, S. Saarinen, K. Tiitinen, T. Keskinen, M. Luhtala, O. Koskinen, J. Okkonen, and R. Raisamo, "Seek'N'Share: a platform for location-based collaborative mobile learning," in Proceedings of the $12^{\text {th }}$ International Conference on Mobile and Ubiquitous Multimedia, 13, 38, 2013. http://dx.doi.org/10.1145/2541831.2541872

[9] M. Sharples, "Education in the wild: contectual and location-based mobile learning in action", A report from STELLAR Apline Rendez-Vous workshop series. 2010.

[10] S. Deterding, R. Khaled, L. E. Nacke, and D. Dixon, "Gamification: Toward a Definition", in Gamification Workshop Proceedings, Vancouver, BC, Canada, 2011

[11] S. Deterding, D. Dixon, R. Khaled and L. Nacke, "From Game Design Elements to Gamefulness: Defining 'Gamification"', pp. 9-
15, 2011 [Proceedings of the $15^{\text {th }}$ International Academic MindTrek Conference: Envisioning Future Media Environments, New York, USA] http://dx.doi.org/10.1145/2181037.2181040

[12] C. O'Brien and "O'Brien. Get ready for the decade of gamification, 2010 [Online]. Available: http://www.mercury news.com/ci 16401223

[13] B. Reeves and J. Leighton Read, "Games at Work - How Games and Virtual Worlds Are Changing the Way People Work and Businesses Compete", $1^{\text {st }}$ ed., Perseus Books, Mcgraw-hill Prefessional, Harvard Business School Press, 2009

[14] Duolingo Website. 2010, [Online]. Available: http://www.duo lingo.com/info

[15] Y. Chou. Top 10 Education Gamification Examples that will Change our Future, 2013, [Online]. Available: http://www.yukai chou.com/gamification-examples/top-10-education-gamificationexamples

[16] Khan Academy Website. 2013, [Online]. Available: https://www.khanacademy.org

[17] E. Bruenner. Play to Learn With Khan Academy, 2014, [Online]. Available: http://www.gamification.co/2011/05/26/quests-skilltrees-for-learning-with-khan-academy/

[18] K Fitzke. Office Ribbon Game \& Other Learning Resources, 2013, [Online]. Available: http://office.about.com/b/2011/ 08/13/110.htm

[19] S. Faulkner. Welcome to Ribbon Hero 2, 2011, [Online]. Available: http://www.ribbonhero.com

[20] P. Marx. The Hunter Games, 2012, [Online]. Available: http://www.newyorker.com/reporting/2012/07/02/120702fa_fact_ $\underline{\text { marx }}$

[21] NOAA. Selective Availability, 2013, [Online]. Available: http://www.gps.gov/systems/gps/modernization/sa/data/

[22] Groundspeak. The History of Geocaching, 2014, [Online]. Available: http://www.geocaching.com

[23] G. Clough, "Geolearners: Location-Based Informal Learning with Mobile and Social Technologies", IEEE Trans. Learn. Technol. 3, 1, 33-44, 2010. http://dx.doi.org/10.1109/TLT.2009.39

[24] B. Spiegel. Geo-Location, Geo-Fencing \& Creep Factor: The Future of Location Data and Mobile Advertising, 2013, [Online]. Available: http://www.clickz.com/clickz/column/2299940/geolocation-geo-fencing-creep-factor-the-future-of-location-data-andmobile-advertising

[25] B. Cha, Out and About Town With Two Travel Discovery Apps, 2013, [Online]. Available: http://allthingsd.com/20130110/outand-about-town-with-two-travel-discovery-apps/

[26] K. Schrier. About, 2014, [Online]. Available: http://karenschrier.wordpress.com

[27] K. Schrier. Student Postmortem: Reliving the Revolution, 2006, [Online]. Available: http://www.gamecareerguide.com/features/ 263/student_postmortem_reliving the_php?page $=1$

[28] R. Wetzel, L. Blum, and L. Oppermann, "Tidy City- A locationbased game supported by in-situ and web-based authoring tools to enable user-created content," in Proceedings of the International Conference on the Foundations of Digital Games, 12, pp. 238-241, 2012.

\section{AUTHORS}

J. Pirker is with the Graz University of Technology, Graz, Austria (e-mail: jpirker@iicm.edu).

C.Guetl., is with Graz University of Technology, Graz, Austria and Curtin University, Perth, Western Australia (e-mail: cguetl@iicm.edu).

P. Weiner is with Graz University of Technology, Graz, Austria. (e-mail: pawe@sbox.tugraz.at).

V. M. Garcia-Barrios is with Galileo University, Guatemala City, Guatemala. (e-mail: vgarcia@galileo.edu).

This article is an extended and modified version of a paper presented at the International Conference of Interactive Mobile and Computer Aided Learning (IMCL2014), held in November 2014, in Thessaloniki, Greece. Submitted, January, 10, 2015. Published as resubmitted by the authors on May, 18, 2015. 